\title{
Potencialidades de um caulim calcinado como material de substituição parcial do cimento portland em argamassas
}

\author{
Marilia P. de Oliveira ${ }^{1} \&$ Normando P. Barbosa ${ }^{2}$
}

\begin{abstract}
RESUMO
A utilização de argilas calcinadas na forma de metacaulinita, como material pozolânico para argamassas e concretos, tem recebido atenção considerável nos últimos anos. Este trabalho objetivou avaliar o desempenho mecânico de argamassas, nas quais foi utilizado um caulim calcinado proveniente do Estado da Paraíba, como material de substituição parcial do cimento Portland. Utilizaram-se duas finuras do caulim: passando nas peneiras ABNT $200(0,074 \mathrm{~mm})$ e $325(0,044 \mathrm{~mm})$ e calcinados nas temperaturas de 700,800 e $900{ }^{\circ} \mathrm{C}$ pelo tempo de $2 \mathrm{~h}$. As amostras foram caracterizadas através de análise química, análise térmica diferencial, difração de raios-X e área específica. Obteve-se o índice de atividade pozolânica com a cal e o cimento Portland. O percentual de substituição adotado foi de 0, 10, 20, 30 e 40\%. A relação aglomerante: areia foi de 1:1,5 e a relação água/aglomerante fixada igual 0,4. O efeito da substituição parcial do cimento na argamassa foi avaliado através da resistência à compressão simples, nas idades de 7, 28 e 90 dias. As argamassas estudadas apresentaram resistência superior em relação à da referência, até o nível de $30 \%$ de substituição.
\end{abstract}

Palavras-chave: pozolana, argila calcinada, atividade pozolânica

\section{Potentialities of a calcined kaolin as material of partial replacement of portland cement in mortars}

\begin{abstract}
The use of burnt clays, in the metakaolin form, as pozzolanic material for mortars and concretes has received a remarkable attention in the last years. This paper aimed to evaluate the mechanical property of mortars, in which a calcined kaolin originating from the State of Paraiba, was used as partial cement replacement material. Two finess of the kaolin were used: ABNT $200(0.074 \mathrm{~mm})$ and $325(0.044 \mathrm{~mm})$ and burnt at temperatures of 700,800 and $900{ }^{\circ} \mathrm{C}$ for a period of $2 \mathrm{~h}$. Both materials were characterized by chemical analysis, differential thermal analysis, X-ray diffraction, specific area tests. The pozolanic activity index was obtanied using lime and cement Portland. The amounts of replacement were $10,20,30$ and $40 \%$, besides the reference mortar. The binder: sand ratio was 1:1.5 and the water/binder ratio was constant and equal to 0.4. The effect of partial substitution of cement in mortar was evaluated through compressive strength at 7, 28 and 90 days. Mortars with kaolin presented superior strength comparing to reference mortar, up to the level of $30 \%$ of substitution.
\end{abstract}

Key words: pozzolana, calcined clay, pozolanic activity 


\section{INTRODUÇÃO}

A principal propriedade de uma pozolana é a sua capacidade de reagir e se combinar com o hidróxido de cálcio, formando compostos estáveis de poder aglomerante, tais como: silicatos e aluminatos de cálcio hidratados, assim, no cimento Portland o hidróxido de cálcio liberado pela hidratação dos silicatos, reage com a pozolana, utilizada como substituição parcial do cimento, resultando em uma produção extra de silicatos de cálcio hidratados, que são produtos mais estáveis do cimento hidratado.

O uso de argilas calcinadas como misturas pozolânicas de cimento, é conhecido desde o tempo dos romanos. As principais razões para o uso das argilas calcinadas em argamassas e concretos se ligam à sua disponibilidade e ao aumento da durabilidade por elas provocado (Sabir et al., 2001).

As argilas mais utilizadas para a produção de pozolana são as caulinitas, montmorilonitas e as ilitas (Santos, 1992). O aproveitamento da argila caulinita calcinada como adição pozolânica moderna para argamassas e concreto, tem-se popularizado nos últimos anos (Shvarzman et al., 2003). A argila caulinita sofre alterações em suas propriedades físicas e químicas, quando submetida a tratamentos térmicos. A metaculinita $\left(\mathrm{Al}_{2} \mathrm{Si}_{2} \mathrm{O}_{7}\right)$ é um produto amorfo resultante do processo de desidroxilação da caulinita, através da calcinação em temperaturas controladas. A temperatura de calcinação das argilas afeta a atividade pozolânica do produto resultante. A argila se torna mais reativa quando conduz à perda da hidroxila, resultando em colapso e desarranjo da estrutura da argila. Segundo Kakali et al. (2001), o desenvolvimento das propriedades pozolânicas de argilas calcinadas depende da natureza e da abundância do argilomineral, das condições de calcinação e da finura do produto final. As propriedades pozolânicas são desenvolvidas por calcinação a cerca de $500{ }^{\circ} \mathrm{C}$, cujas temperaturas ótimas são entre 700 e $900{ }^{\circ} \mathrm{C}$ (Santos, 1992).

Algumas das vantagens técnicas resultantes do emprego de pozolanas em concretos, são as seguintes: a reação álcali-agregado pode ser reduzida ou inibida; a resistência mecânica pode ser aumentada; a resistência a cloretos, sulfatos e água do mar, pode ser melhorada; a permeabilidade pode ser reduzida e a liberação de calor é diminuída. Além dessas vantagens técnicas, tem-se o benefício econômico obtido por um consumo menor de cimento Portland, mantendo ou aumentando a resistência mecânica e melhorando a durabilidade. Pela mesma razão, uma economia de energia pode ser atingida: os materiais pozolânicos são energeticamente mais econômicos que o clínquer do cimento Portland, o uso de pozolanas tem implicações ecológicas, contribuindo para um aproveitamento melhor dos resíduos industriais poluidores, como é caso das cinzas volantes transportadas pelos gases de exaustão das termelétricas, da microssílica oriunda das indústrias de ferro-silício e silício metálico (Zampieri, 1989), e até mesmo os resíduos de cerâmica moída.

Com este trabalho, objetivou-se avaliar o desempenho mecânico de argamassas, nas quais foi utilizado um caulim calcinado proveniente do Estado da Paraíba, como material de substituição parcial do cimento Portland.

\section{MATERIAL E MÉTODOS}

O cimento utilizado foi o cimento Portland CP II F 32 e o caulim empregado foi fornecido pela Caulisa S.A, localizada no Município de Juazeirinho, PB. Utilizaram-se duas finuras do caulim, uma que passa na peneira \#200 e outra que passa na peneira \#325. As amostras foram calcinadas em temperaturas de 700,800 e $900{ }^{\circ} \mathrm{C}$ em um forno elétrico de marca Elektro Therm, durante 2 h, a fim de se obter metacaulinita. O agregado miúdo utilizado na produção das argamassas foi uma areia quartzosa proveniente do rio Paraíba e água potável, fornecida pela concessionária de abastecimento da cidade de João Pessoa, PB. Também se fez uso de um superplastificante à base de policarboxilatos, com teor de sólidos de $30 \%$ e densidade de 1,12.

Para o trabalho experimental, foram realizados os seguintes ensaios:

Análise química: feita no Laboratório de Análises Minerais do CCT, da Universidade Federal de Campina Grande.

Análise térmica diferencial (ATD): realizada com um aparelho da marca BP Engenharia, modelo RB 3000, operando a $12,5{ }^{\circ} \mathrm{C} \mathrm{min}^{-1} \mathrm{com}$ temperatura máxima de $1000{ }^{\circ} \mathrm{C}$ e o padrão utilizado foi o óxido de alumínio $\left(\mathrm{Al}_{2} \mathrm{O}_{3}\right)$ calcinado.

Difração de raios-X (DRX): efetuada em um equipamento XRay Diffractometer da marca Siemens, modelo D 5000, operando com radiação K-alfa de ferro, $30 \mathrm{kV}$ e $30 \mathrm{~mA}$, com varredura entre $2 \theta\left(15^{\circ}\right)$ e $2 \theta\left(110^{\circ}\right)$.

Área específica: foi determinada segundo a NBR 7224 (ABNT 1984) que prescreve o método para a determinação da área específica de cimentos e outros materiais em pó empregando o permeâmetro de Blaine.

Índice de atividade pozolânica com a cal: o ensaio para determinação da atividade pozolânica com a cal foi realizado conforme a prescrição da NBR 5751 ABNT (1992a). Este ensaio é uma medida direta do grau de pozolanicidade através da determinação da resistência a compressão simples, conforme NBR 7215 ABNT (1996), de corpos-deprova de argamassas preparadas com o material em estudo, cal, areia e água, curadas nos próprios moldes durante $24 \pm 2 \mathrm{~h}$ a temperatura de $23 \pm 2{ }^{\circ} \mathrm{C}$ e durante seis dias a temperatura de $55 \pm 2{ }^{\circ} \mathrm{C}$.

Índice de atividade pozolânica com o cimento: o ensaio para determinação da atividade pozolânica com o cimento foi realizado conforme a prescrição da NBR 5752 ABNT (1992b). O índice de atividade pozolânica é dado pela relação entre a resistência da argamassa com o material pozolânico e a resistência à compressão da argamassa de referência.

Para se verificar o desempenho do caulim calcinado (metacaulinita) como material de substituição parcial do cimento Portland, prepararam-se argamassas com taxas de substituição do cimento de 10, 20, 30 e 40\%. Como referência, foram usadas também argamassas com $0 \%$ de substituição. A relação aglomerante:areia foi de 1:1,5 em massa, enquanto a relação água/aglomerante foi mantida constante em 0,4. Para se obter a consistência aproximadamente igual das 
argamassas, fez-se uso de superplastificante. Utilizou-se o ensaio de consistência realizado na mesa de fluidez, de acordo com a norma NBR 13276 ABNT (1995), que prescreve o espalhamento de $255 \pm 10$ mm em diâmetro da argamassa sobre a mesa para ser considerada consistência normal. Os corpos-de-prova foram moldados utilizando-se moldes cilíndricos com dimensões 5 x $10 \mathrm{~cm}$ e, após a desmoldagem, foram submetidos a cura submersa por períodos de 7 , 28 e 90 dias, em temperatura ambiente. A resistência à compressão das argamassas foi obtida pelo ensaio indicado na NBR 7215 ABNT (1996).

\section{RESULTADOS E DISCUSSÃO}

\section{Análise química}

Os resultados obtidos nas análises químicas das amostras do caulim in natura estão apresentados na Tabela 1. As amostras do caulim apresentaram teores de $\mathrm{SiO}_{2}$ de 47,41\% (caulim \#200) e 45,70\% (caulim \#325) e teores de $\mathrm{Al}_{2} \mathrm{O}_{3}$ de 38,00 e 39,30\%, respectivamente. Esses valores se aproximam dos especificados por Santos (1992), de 46,5\% para o $\mathrm{SiO}_{2}$ e $39,5 \%$ para o $\mathrm{Al}_{2} \mathrm{O}_{3}$. A soma dos percentuais de $\mathrm{SiO}_{2}, \mathrm{Al}_{2} \mathrm{O}_{3}$ e $\mathrm{Fe}_{2} \mathrm{O}_{3}$ é de 85,81 e 85,40\% para o caulim \#200 e o caulim \#325 respectivamente, superando os valores mínimos de 70\% propostos pela C-618 ASTM (1989) e NBR 12653 ABNT (1992c).

Tabela 1. Composição química das amostras do caulim in natura

\begin{tabular}{crr}
\hline Determinações (\%) & \#200 & \#325 \\
$\mathrm{SiO}_{2}$ & 47,41 & 45,70 \\
$\mathrm{Al}_{2} \mathrm{O}_{3}$ & 38,00 & 39,30 \\
$\mathrm{Fe}_{2} \mathrm{O}_{3}$ & 0,40 & 0,40 \\
$\mathrm{CaO}$ & Traços & Traços \\
$\mathrm{Mg} \mathrm{O}$ & Traços & Traços \\
$\mathrm{K}_{2} \mathrm{O}$ & 0,50 & 0,28 \\
$\mathrm{Na}_{2} \mathrm{O}$ & 0,08 & 0,07 \\
Perda ao Rubro & 12,48 & 13,81 \\
Resíduo Insolúvel & 0,71 & 0,59 \\
\hline
\end{tabular}

\section{Análise térmica diferencial (ATD)}

Encontram-se na Figura 1, os termogramas das amostras do caulim in natura. $\mathrm{Na}$ análise termodiferencial do caulim \#200, observam-se picos característicos da perda de umidade e água adsorvida a aproximadamente $175{ }^{\circ} \mathrm{C}$. A partir de $540{ }^{\circ} \mathrm{C}$ inicia-se a reação de desidroxilação completada pelo pico endotérmico, a $600{ }^{\circ} \mathrm{C}$, condições em que se forma a metacaulinita. A cerca de $980{ }^{\circ} \mathrm{C}$ a metacaulinita se transforma em mulita (Santos, 1992). Na curva termodiferencial do caulim \#325, faz-se a mesma observação, ou seja, o termograma é praticamente idêntico ao do caulim \#200, como era previsto.

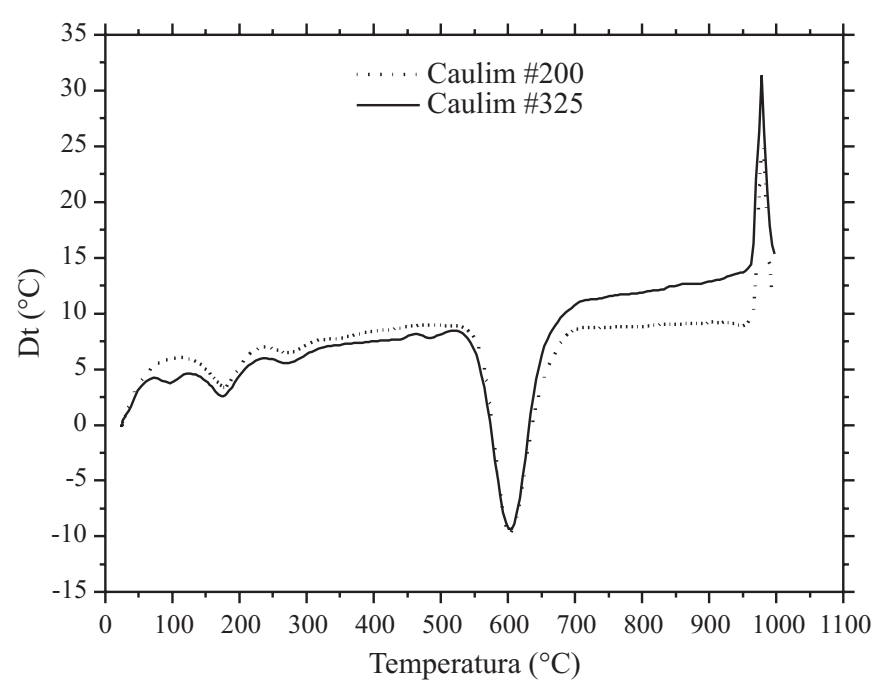

Figura 1. Termograma das amostras do caulim in natura

\section{Difração de raios-x (DRX)}

Nos difratogramas (Figura 2) encontram-se reproduzidos os difratogramas das amostras de caulim in natura e calcinadas. No difratograma do caulim in natura observamse picos correspondentes aos seguintes compostos: caulinita $(7,18,3,58$ e $1,66 \AA)$ e quartzo $(4,20,3,35$ e $2,56 \AA)$ para o caulim \#200. Na amostra de caulim \#200-700 ${ }^{\circ} \mathrm{C}$ encontram-se picos de mica (9,99 e 5,04 $\AA$ ) e de quartzo $(4,20,3,34$ e $3,24 \AA)$, para o caulim \#200-800 ${ }^{\circ} \mathrm{C}$ encontram-se picos de mica $(9,94$ e $5,00 \AA)$ e de quartzo $(4,19$, 3,34 e 2,51 $\AA$ ), para o caulim \#200-900 ${ }^{\circ} \mathrm{C}$ tem-se picos de mica $(9,87$ e $4,98 \AA$ ) e de quartzo (4,20, e $3,23 \AA)$. No difratograma do caulim \#325 in natura tem-se picos de caulinita $(7,17,3,58$ e $2,34 \AA)$ e quartzo $(4,46,3,35$ e 2,38 $\AA$ ), enquanto para a amostra do caulim \#325-700 ${ }^{\circ} \mathrm{C}$ se encontram picos de mica $(9,99$ e $5,04 \AA)$ e de quartzo (3,33 $\AA$ ), para o caulim \#325-800 ${ }^{\circ} \mathrm{C}$ apresentam-se picos de mica $(9,94$ e $5,00 \AA)$ e de quartzo (3,85 $\AA$ ), e caulim \#325-900 ${ }^{\circ} \mathrm{C}$ são encontrados picos de mica $(9,87,4,98 \AA$ ) e de quartzo (3,34 $\AA$ ). Observa-se também que, para todas as amostras dos caulins calcinadas, os picos de caulinita desaparecem, conseqüência da quebra da sua estrutura cristalina, que se torna amorfa.

\section{Área específica}

Os resultados obtidos para as áreas específicas das amostras dos caulins in natura e calcinadas, encontram-se na Tabela 2. As amostras de caulim indicaram valores de 2,13 e 2,58 $\mathrm{m}^{2} \mathrm{~g}^{-1}$ para os caulins \#200 e \#325 respectivamente,

Tabela 2. Áreas específicas das amostras de caulim in natura e calcinadas determinadas pelo método de BLAINE

\begin{tabular}{ccccc}
\hline \multirow{2}{*}{ Amostras } & \multicolumn{4}{c}{ Àrea Específica $\left(\mathbf{m}^{\mathbf{2}} \mathbf{g}^{-1}\right)$} \\
\cline { 2 - 5 } Caulim \#200 & In natura & $\mathbf{7 0 0}{ }^{\circ} \mathbf{C}$ & $\mathbf{8 0 0}{ }^{\circ} \mathbf{C}$ & $\mathbf{9 0 0}{ }^{\circ} \mathbf{C}$ \\
Caulim \#325 & 2,13 & 2,09 & 1,93 & 1,97 \\
\hline
\end{tabular}


Potencialidades de um caulim calcinado como material de substituição parcial do cimento portland ...
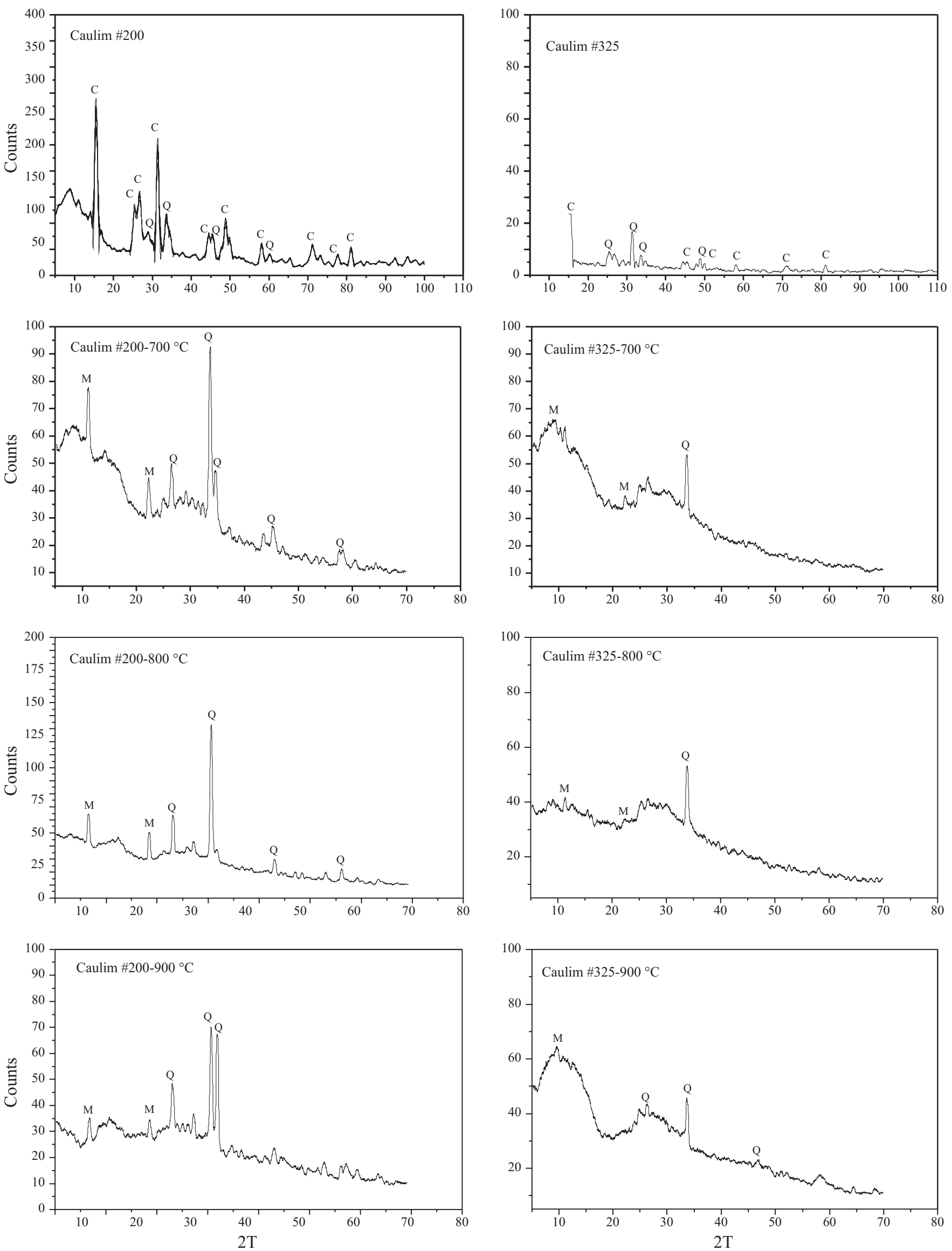

C - Caulinita; M - Mica; Q - Quartzo 
próximos dos encontrados por Oliveira (1995), que foram de 2,03 e 2,36 $\mathrm{m}^{2} \mathrm{~g}^{-1}$ para caulins de mesma procedência e finura. Para as amostras calcinadas, as áreas específicas variaram de 1,93 a 2,09 $\mathrm{m}^{2} \mathrm{~g}^{-1}$ para o caulim \#200 e de 2,15 a $2,50 \mathrm{~m}^{2} \mathrm{~g}^{-1}$ para o caulim \#325. Constata-se decréscimo das áreas específicas com a calcinação, uma vez que ocorre aglomeração dos grãos quando eles são submetidos a altas temperaturas. De qualquer forma, o material apresenta finura superior à do cimento Portland, que é da ordem de $0,28-0,55 \mathrm{~m}^{2} \mathrm{~g}^{-1}$.

\section{Índice de atividade pozolânica com a cal}

Na Tabela 3 são apresentados os resultados obtidos no ensaio do índice de atividade pozolânica com a cal das amostras do caulim calcinado. Os resultados são as médias de três corpos-de-prova, expressos em MPa, com desvio relativo máximo calculado de acordo com as prescrições da NBR 7215 ABNT (1996), menor que 6\%. Segundos os resultados obtidos, constatou-se variação dos valores da resistência média para uma mesma finura nas diferentes temperaturas. O caulim \#200 calcinado nas três temperaturas, variou de 7,0 a 8,5 $\mathrm{MPa}$, enquanto o caulim \#325 calcinado mostrou resultados um pouco melhores, oscilando entre 7,5 a 8,2 MPa. Segundo a NBR 12653 ABNT (1992c), são considerados pozolânicos os materiais que apresentam o índice de atividade pozolânica com cal, aos 7 dias, cuja resistência à compressão simples deve ser igual ou superior a 6,0 $\mathrm{MPa}$. De acordo com esta especificação, o caulim calcinado pode ser considerado material pozolânico, pois apresentou valores superiores àquele limite.

Tabela 3. Índice de atividade pozolânica com a cal das amostras de caulim calcinadas nas diversas temperaturas

\begin{tabular}{ccccc}
\hline \multirow{2}{*}{ Argamassas } & \multicolumn{3}{c}{ RCS (MPa) } & Média \\
\cline { 2 - 4 } \#200-700 ${ }^{\circ} \mathrm{C}$ & $\mathbf{1}$ & $\mathbf{2}$ & $\mathbf{3}$ & \\
\#200-800 ${ }^{\circ} \mathrm{C}$ & 8,2 & 7,7 & 6,6 & 7,1 \\
\#200-900 ${ }^{\circ} \mathrm{C}$ & 7,2 & 8,9 & 8,5 & 8,5 \\
$\# 325-700^{\circ} \mathrm{C}$ & 8,2 & 8,3 & 7,0 & 7,0 \\
$\# 325-800^{\circ} \mathrm{C}$ & 7,6 & 7,6 & 8,0 & 8,2 \\
\#325-900 ${ }^{\circ} \mathrm{C}$ & 8,0 & 8,2 & 8,1 & 7,5 \\
\hline
\end{tabular}

RCS-Resistência à Compressão Simples

\section{Índice de atividade pozolânica com o cimento}

Apresentam-se na Tabela 4 os resultados obtidos para os ensaios do índice de atividade pozolânica com o cimento das amostras do caulim, calcinadas nas diferentes tempe-
Tabela 4. Índice de atividade pozolânica com o cimento das amostras de caulim, calcinadas nas diversas temperaturas

\begin{tabular}{|c|c|c|c|c|c|}
\hline \multirow{2}{*}{ Argamassas } & \multicolumn{3}{|c|}{ RCS (MPa) } & \multirow{2}{*}{ Média } & \multirow{2}{*}{$\begin{array}{l}\text { I. A. P. } \\
\text { CP (\%) }\end{array}$} \\
\hline & 1 & 2 & 3 & & \\
\hline Referência & 30,2 & 32,1 & 30,9 & 31,1 & - \\
\hline$\# 200-700{ }^{\circ} \mathrm{C}$ & 25,0 & 27,3 & 27,8 & 26,7 & 86,0 \\
\hline$\# 200-800{ }^{\circ} \mathrm{C}$ & 30,0 & 32,2 & 30,5 & 30,9 & 99,4 \\
\hline$\# 200-900{ }^{\circ} \mathrm{C}$ & 31,6 & $34,4^{*}$ & 30,1 & 30,8 & 99,0 \\
\hline$\# 325-700{ }^{\circ} \mathrm{C}$ & 28,7 & $31,7^{*}$ & 28,7 & 28,7 & 92,2 \\
\hline$\# 325-800{ }^{\circ} \mathrm{C}$ & 31,6 & 29,4 & 31,3 & 30,8 & 99,0 \\
\hline$\# 325-900^{\circ} \mathrm{C}$ & $23.9 *$ & 29,5 & 28,8 & 29.1 & 93,6 \\
\hline
\end{tabular}

raturas. Os resultados do índice de atividade pozolânica com cimento, variaram de 86,0 a 99,4\% para o caulim \#200 e 92,2 a 99,0\% para o caulim \#325. A NBR 12653 ABNT (1992c) estipula um valor mínimo de $75 \%$ para o índice de atividade pozolânica com o cimento. Portanto, os caulins \#200 e \#325, calcinados nas diferentes temperaturas, apresentaram índices de atividade pozolânica com o cimento satisfatórios, superiores a $75 \%$.

\section{Resistência à compressão simples}

Os resultados gráficos das resistências à compressão simples dos corpos de prova curados aos 7, 28 e 90 dias das amostras de caulim calcinado e argamassas de referência sem substituição, são apresentados na Figura 3, na qual se verifica que, com $30 \%$ de substituição do cimento Portland por caulim calcinado \#200-700 ${ }^{\circ} \mathrm{C}$ obtém-se o melhor resultado para todos os períodos de cura, enquanto para o caulim calcinado \#325-700 ${ }^{\circ} \mathrm{C}$, $20 \%$ de substituição são suficientes para se obter melhor resultado em relação às demais substituições, isto se deve a uma quantidade extra de silicatos de cálcio hidratado produzido pela reação entre o hidróxido de cálcio, produto da hidratação do cimento e o caulim calcinado. Com $40 \%$ de substituição do cimento Portland por caulim calcinado \#200$800{ }^{\circ} \mathrm{C}$ aos 28 e 90 dias de cura, enquanto, com caulim calcinado \#325-800 ${ }^{\circ} \mathrm{C}$ se obteve o melhor resultado, com $30 \%$ de substituição para todos períodos de cura, por outro lado, $40 \%$ de substituição do cimento Portland por caulim calcinado, \#200-900 ${ }^{\circ} \mathrm{C}$, aos 28 e 90 dias de cura e com caulim calcinado \#325-900 ${ }^{\circ} \mathrm{C}$, obteve-se o melhor resultado com $30 \%$ de substituição para todos os períodos de cura. Constata-se, também, que o material mais fino (passando pela peneira $n^{\circ} 325$ ) apresenta melhor desempenho mecânico devido, possivelmente, a sua área específica ser maior e provocar refinamento dos poros e, conseqüentemente, maior resistência. 

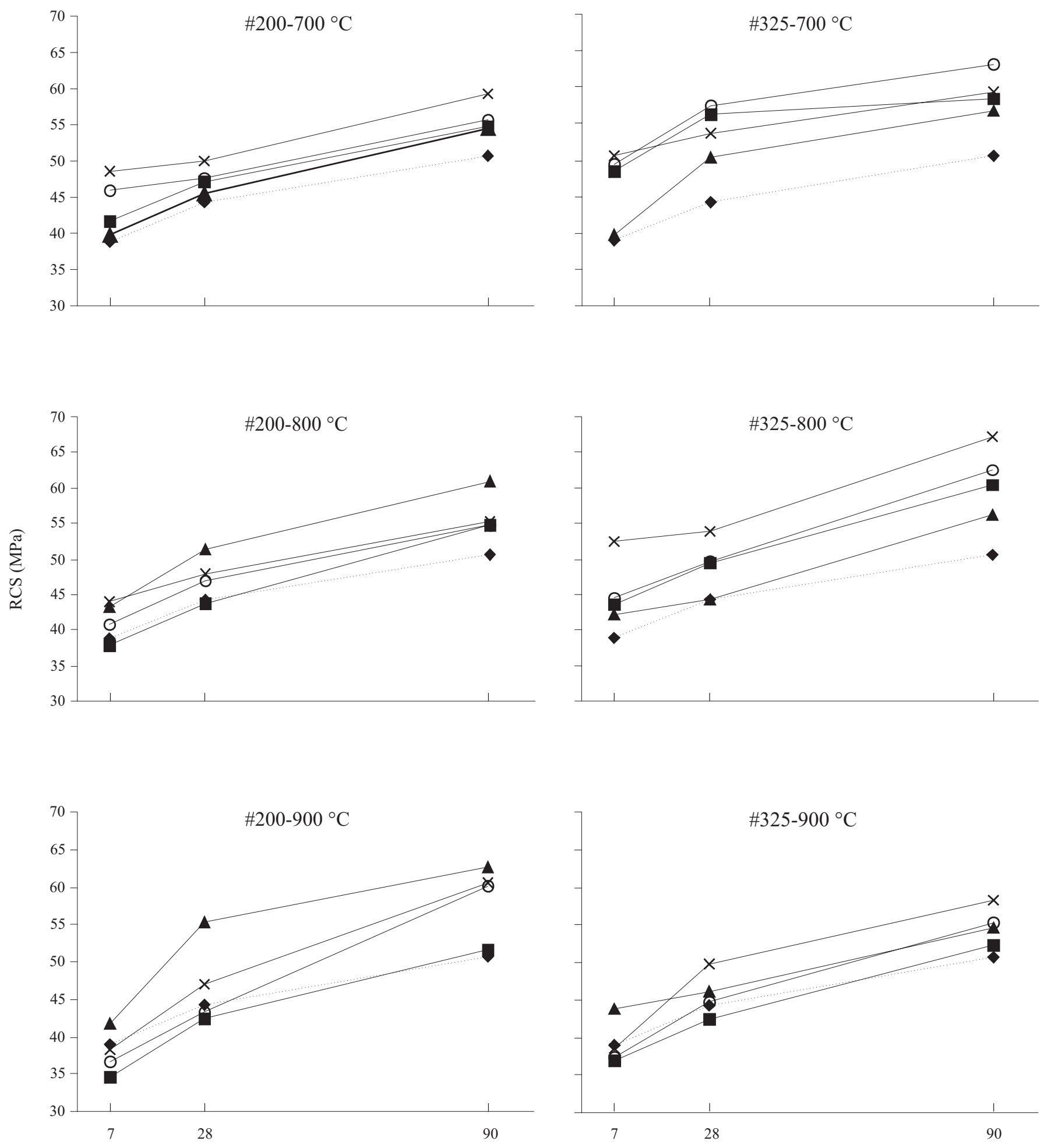

Tempo de Cura (dias)

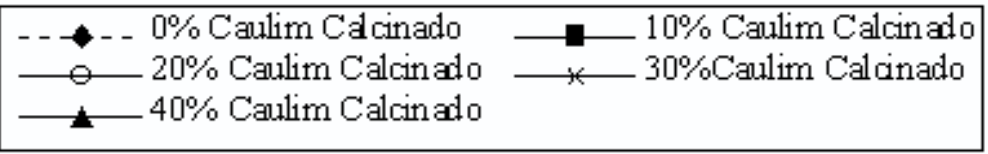

Figura 3. Resistência à compressão simples das argamassas de referência e com caulim calcinado 


\section{CONCLUSÕES}

1. A composição química do caulim utilizado atende aos requisitos da NBR 12653 (1992c), e aos da ASTM Standard (1989) relativas a materiais pozolânicos.

2. O ensaio de ATD confirmou que a faixa de calcinação pode encontrar-se entre 700 e $800{ }^{\circ} \mathrm{C}$. A temperatura de calcinação de $700{ }^{\circ} \mathrm{C}$ é suficiente para obter uma argamassa de melhor resistência e o material passado na peneira $\mathrm{n}^{\circ} 325$ apresenta melhor desempenho.

3. Através do DRX, nota-se que nas temperaturas adotadas para calcinação, a caulinita transformou-se em metacaulinita, com os picos desaparecendo nos difratogramas.

4. Os ensaios que determinam os índices de atividades pozolânicas com a cal e o cimento, respectivamente, demonstraram que o caulim calcinado possui boa atividade pozolânica, com índices acima do exigido pelas respectivas normas.

5. A resistência à compressão é altamente beneficiada quando se substitui parcialmente o cimento Portland pelo caulim calcinado a $700{ }^{\circ} \mathrm{C}$ e em taxas de até $30 \%$ de substituição.

\section{LITERATURA CITADA}

ABNT - Associação Brasileira de Normas Técnicas. NBR 7224 - Cimento Portland e outros materiais em pó - Determinação da área específica. Rio de Janeiro, 1984.

ABNT - Associação Brasileira de Normas Técnicas. NBR 5751 Índice de atividade pozolânica com a cal. Rio de Janeiro, 1992a.

ABNT - Associação Brasileira de Normas Técnicas. NBR 5752 - Materiais Pozolânicos - Determinação da atividade pozolânica com cimento Portland. - Índice de atividade pozolânica com o cimento. Rio de Janeiro, 1992b.
ABNT - Associação Brasileira de Normas Técnicas. NBR 12653 Materiais pozolânicos - Especificação. Rio de Janeiro, 1992c.

ABNT - Associação Brasileira de Normas Técnicas. NBR 13276 - Argamassas para assentamento de paredes e revestimento de paredes e tetos - Determinação do teor de água para obtenção do índice de consistência Padrão, Rio de Janeiro, 1995.

ABNT - Associação Brasileira de Normas Técnicas. NBR 7215 - Determinação da resistência à compressão. Rio de Janeiro, 1996.

ASTM - American Society for Testing and Materials, ASTM C618, Specifications for fly ash and raw or calcined natural pozzolan for use as a mineral admixture in Portland cement, 1989.

Kakali, G.; Perraki, T.; Tsivilis, S.; Bandogiannis, E. Thermal treatment of kaolin: the effect of mineralogy on the pozzolanic activity. Applied Clay Science, London UK, v. 20, p.73-80, 2001.

Oliveira, D. F. Estudo da reação pozolana artificial e cal: Influência do tipo de pozolana, tempo de cura, temperatura de reação e temperatura de calcinação sobre a resistência mecânica das argamassas. CCT/UFPB 1995. 108p. Dissertação Mestrado

Sabir, B. B.; Wild, S. E.; Bai, J. Metakaolin and calcined clays as pozzolans for concrete: a review. Cement \& Concrete Composites, London UK v. 23, p.441-454, 2001.

Santos, P. S. Ciência e Tecnologia de argilas, 2. ed. revisada e ampliada, São Paulo: Edgard Blücher, 1992.

Shvarzman, A.; Kovler, K.; Grader, G. S.; Shter, G. E. The effect of a dhydroxylation/amorphization degree on pozzolanic activity of kaolinite. Cement and Concrete Research, London UK, v. 33, p.405-416, 2003.

Zampieri, V. A. Mineralogia e Mecanismo de ativação e reação das pozolanas de argilas calcinadas, Instituto de Geociências-USP, São Paulo 1989. 191p. Dissertação Mestrado. 